\title{
HIV/AIDS and Psychosocial Ostracism: A view from Kashmir
}

\author{
Mohmad Iqbal $^{1 *}$
}

Keywords: HIV/AIDS, Psychosocial Ostracism, Kashmir.

\section{HIV/AIDS: General Perspective}

Literally the phrasal acronym HIV/AIDS would prove a leitmotif in this study. AIDS is the final stage of HIV infection, and not everyone who has HIV advances to this stage. At this stage people are susceptible to opportunistic infections because of their damaged immune system. So a person progressed to too many opportunistic infections means he has AIDS. He also may show very little CD4 count. A person at this stage is bound to go for medical, salubrious, and therapeutic intervention to avoid the extreme results and death sentence. HIV epidemic has a well-documented and well understood progression. Untreated, HIV is almost universally fatal because it eventually damages the immune system-resulting in acquired immunodeficiency syndrome (AIDS). HIV treatment (antiretroviral therapy) helps people at all stages of the disease, and treatment can slow or prevent progression from one stage to the next. As yet no vaccine or drug has been made by the medical sciences that ensure the complete eradication of virus from the body. The available drugs surely can stop the growth of virus, or lessen the multiplication of it. These drugs have been responsible for the longevity of the HIV infected.

\section{Worldwide HIV \& AIDS Statistics}

HIV/AIDS epidemic is defined by the HIV prevalence in the general population. HIV prevalence is the percentage of the population living with HIV. HIV prevalence is below $1 \%$ in the general population but exceeds $5 \%$ in specific at-risk populations like injecting drug users or sex workers. In order to understand the HIV and AIDS epidemic, it is necessary to look at certain figures. Researchers and epidemiologists usually compile the number of people living with HIV (the HIV prevalence), the number of new infections (the HIV incidence), and the number of people who have died of AIDS among other categories. The latest statistics of the global HIV and AIDS epidemic were published by UNAIDS, WHO and UNICEF in July 2014, and refer to the end of 2013. The number of people living with HIV/AIDS in the end of 2013 was 35 million. About 3.2 million are under the age of 15. In 2013, an estimated 2.1 million people were newly infected with HIV and 240,000 were under the age of 15. Every day more than 5,700 people contract HIV-nearly 240 every hour. In 2013, 1.5 million people died from AIDS. As of March 2015, 15 million people living with HIV were receiving antiretroviral

\footnotetext{
${ }^{1} \mathrm{PhD}$ Research Scholar, Dept. of Social Work, MANUU

*Responding Author

(C) 2016 I M Iqbal; licensee IJIP. This is an Open Access Research distributed under the terms of the Creative Commons Attribution License (http://creativecommons.org/licenses/by/2.0), which permits unrestricted use, distribution, and reproduction in any Medium, provided the original work is properly cited.
} 
treatment. 59\% of people living with HIV are still not accessing treatment. Since the beginning of the pandemic, nearly 78 million people have contracted HIV and close to 39 million have died of AIDS-related causes.

\section{Social Exclusion, Stigma and HIV/AIDS}

HIV/AIDS stigma and discrimination exists worldwide, although they manifest themselves differently across countries, communities, religious groups and individuals. Fear of contagion coupled with negative, value-based assumptions about people who are infected leads to high levels of stigma surrounding HIV and AIDS. The stigma is due to some unavoidable facts or even perceptions. HIV/AIDS is a life-threatening disease, and therefore people react to it in strong ways. HIV infection is associated with behaviours (such as homosexuality, drug addiction, prostitution or promiscuity) that are already stigmatized in many societies. Most people become infected with HIV through sex, which often carries moral baggage. There is a lot of inaccurate information about how HIV is transmitted, creating irrational behaviour and misperceptions of personal risk. Religious or moral beliefs lead some people to believe that being infected with HIV is the result of moral fault (such as promiscuity or 'deviant sex') that deserves to be punished. The effects of antiretroviral therapy on people's physical appearance can result in forced disclosure and discrimination based on appearance. The fact that HIV/AIDS is a relatively new disease also contributes to the stigma attached to it. The fear surrounding the emerging epidemic in the 1980s is still fresh in many people's minds.

Stigma may also vary depending on the dominant transmission routes in the country or region. In sub-Saharan Africa, for example, heterosexual sex is the main route of infection, which means that AIDS-related stigma in this region, is mainly focused on promiscuity and sex work. "Because it is about sex, in my country they then automatically think you got it because you have been loose...you are not anything better than a prostitute... they don't believe you didn't get it any other way." - African woman in the UK. In Western countries where injecting drug use and sex between men have been the most common sources of infection; it is these behaviours that are highly stigmatized. Women with HIV or AIDS may be treated very differently from men in some societies especially the male dominated one. "Even a married woman who has been infected by her husband will be accused by her in-laws... In such a male-dominated society no-one ever accepts that the man is actually the one who did something wrong... It is even harder on women since it is seen as a fair result of their sexual misbehaviour." - HIV-positive woman, Lebanon.

AIDS-related stigma has had a profound effect on the epidemic's course. The WHO cites fear of stigma and discrimination as the main reason why people are reluctant to be tested, to disclose their HIV status or to take antiretroviral drugs. Some of these consequences refer to internal stigma' or 'self-stigma'. Internal stigma refers to how people living with HIV regard themselves, as well as how they see public perception of people living with HIV. "I am afraid of giving my disease to my family members-especially my youngest brother who is so small. It would be so pitiful if he got the disease. I am aware that I have the disease so I do not touch him-I talk with 
him only. I don't hold him in my arms now." A Woman in Vietnam says”. Self-stigma and fear of a negative community reaction can hinder efforts to address the AIDS epidemic by perpetuating the wall of silence and shame surrounding the epidemic.

\section{Reading HIV/AIDS and Exclusion in Kashmir}

It has been more than two decades of time Kashmir is living with HIV/AIDS. No matter the first case was reported in 1986, the same year India reports its first case, HIV has not been hovering over valley the way it does to whole of India. Fortunately the number of HIV positive patients is still counted on finger tips. The pandemic has not drastically engulfed the valley, as it does as per its characteristic features and transmission. Kashmir has been so lucky being almost away of the treason of the pandemic to a larger extent. At the same time the fact cannot be overruled that Kashmir is living with this virus since 1986. Valley is suffering the way others do, but may be on smaller scale. The poverty, exclusion, stigma, hatred, discrimination, and prejudice viz-a-viz HIV/AIDS may have least extensions in terms of Kashmir as compared to other States of the country. The question is not only what are the reasons and ways HIV/AIDS spread in Kashmir, but the question why HIV couldn't make its avenues powerful in the valley. Why is there a little number of HIV patients, even when the circumstances like illiteracy, unawareness, and backwardness, were in favour of such transmissions and spread. The study is necessarily based on field study and a well demonstrated questionnaire formulated on the basis of the nature of the HIV/AIDS pandemic. Different dimensions of exclusion have been separately put into course and have been analyzed, processed and explained differently.

\section{Reaction when hearing the status of HIV Positive}

The very basic fact about the epidemic HIV/AIDS is that the death is certain because it is still incurable and no vaccine can help eradicate the virus from the body. No doubt the patient lives long years of healthy life, but, the ring of death keeps the person always on pins. The very first response of an HIV positive person after knowing his/her HIV status is quite scary and rattling. There was diversity in blenching responses from the respondents. Some of them have literally floored down to earth. It seems to them a kind of death announcement. The positive status

proved fatal to some of the patients, and lost their strength to struggle against the diseases. They seem just broken inside with pale traduced complexions.

\section{Firsthand Response of Family Members}

The next encounter is at home. Here it is worth to see the reaction of family members. The characteristics of HIV/AIDS will definitely tell upon its stigmatizing and hateful attributes. It shows quite well 68 percent of respondents say that they have been encouraged and taken care of since they were tested positive. Further 24 percent said that some of the family members started to show a cold shoulder for the reason they are afraid of the circumstances if get touched with any HIV positive, as they have still certain misconceptions regarding the transmission of HIV. 
The very least percentage of eight replied in affirmative when asked if they were abused sometimes being HIV positive.

\section{Effect on Marital Relationship}

Usually it is seen that there is a direct impact of HIV on marital or sex relationships. It is a virus that has got the sexual track the primary reason to get transmitted. So it is impossible naturally to get together when one spouse among the two tests positive for HIV. Further there cannot be any sexual relation any more without any proper protection. It clearly defines the reaction of spouse when getting to know the HIV status of his/her spouse. Fourteen percent of respondents are already widow or widower and sixteen percent of all are unmarried. The remaining seventy percent have many different things to say. The majority of 44 percent says that their spouses started to take much care of them. Although eight percent say their husband/wife started to dislike him/her and the same percentage says that there was no difference in relationship at all. Six percent say the relationship got deteriorated and four percent people's marriages saw the drastic outcome in the form of divorce or separation.

\section{Reaction of Mates and Friends}

Mates and friends are a very important part of one's social life. These get changed at different levels of life and new faces replace the previous one. At every stage their role is quite serious, interesting, and needful. When talking about the impact of HIV on such relationships is quite serious. The relations thus can get collapsed. This question identified the fact of stigma which is attached to HIV and AIDS. The close friends may get detached after their friend has been declared Positive for HIV. Fifty two percent of the respondents experienced the partial abandonment from their close mates and friends. The major reason for this may be the fear of transmission of HIV. The ten percent say that was not a prominent change in such relationships as in before and after. A very less percent of 4 say that they experienced complete abandonment from their friends.

\section{Complications faced in Reaching out Health Centers}

There are certain chances of getting ostracized at different places and settings like marriage, place of worship, bus, train, workplace, hospital and others. HIV positive people are susceptible of getting excluded on their HIV positive statuses. The above chart identifies the intensity of care and treatment by the medical faculty. Seventy eight percent of the respondents admit that they do not face any complications from the medical faculty while availing the medical facilities. Yes about twenty two percent somehow where not happy with the facilities for the reason they are supposed to visit the ART Center Srinagar each month to get a month's long medication course. There are some very poor who can't afford even the bus fare. For such reasons they seemed unhappy with the medical administration and Government policies. The medical staff along with the patients does cry for more ART centers in Kashmir. 


\section{HIV/AIDS and Psychosocial Ostracism: A view from Kashmir}

\section{Attitude of Doctors and Exploitation faced in Hospitals}

As explained above the HIV patients get stigmatized in different social settings. Hospital is the only place where they need to disclose all their secrets related to their health. They get tested and all the health statuses are apparent. They can't keep secrets; they are supposed to share what they are and suffer. The question defines if the HIV patients get full-fledged treatment and care by Medical faculty they are concerned with. For this question ninety six percent replied in affirmative and only four percent replied in negative.

\section{Care Taker at Home}

HIV positive patient usually don't need so much of care as the other ill persons do. An HIV positive person can live several years of healthy life. He can get engaged in day to day tasks and job. He has nothing to worry about if he is on proper medication. Yes there are chances of opportunistic infections or chances of getting weaker day by day. That is why he/she needs proper and nutritious food and regular testing and checkups and follow-ups.

It explains the fact that a maximum of fifty two percent of HIV positive patients are being cared by their respective spouses. This identifies the love and care between husband and wife. The spouse is the first person when it comes to health issues especially when parents are quite older. Sixteen percent of the respondents say that their parents take care of them because most of such patients are either unmarried or much younger. Fourteen percent take care by themselves for the reason they don't expose their HIV status to others. Ten percent are cared by children who must have progressed in age and eight percent of patients are cared by siblings (brothers or sisters).

\section{Impact of Disease (HIV/AIDS) on mental state}

The disease seemingly has lasting impact on the total personality of man. In other words the trajectory or plight takes HIV patient somewhere else than it was projected before. The disease changes the course of life. It adds more chaos, uncertainty, disturbance, imbalance, dependence and much more to life. It stressfully insists a man think differently. For example, during the field study and interviewing the patients while replying some of the questions they felt broken, and some of them started crying literally. As most of them are Muslims and hence believers and God fearing, they open-heartedly said that they spend most of the time remembering Almighty God and prayers (salah). Most of them prostrate, and supplicate and repent of their ill doings and mischievousness done in the past. It seems that they have been sentenced to death. This shows a mental condition they are going through. The question, if the patient has felt any kind of mental disturbance or trauma ever. There were some twenty two percent of affirmative and seventy eight percent of negative responses for this query. It means there is quite an influence of being an HIV positive on the mental state. It is disturbing the mental equilibrium.

A sufferer when asked how they feel and what they mean by living with HIV/AIDS, which is

almost something living with death, reply some bitter experiences. They know they are living with a disease which is incurable. They are also aware of the fact that there may some good years 


\section{HIV/AIDS and Psychosocial Ostracism: A view from Kashmir}

of healthy life too on the conditions when living a hygienic and clean life with proper and regular medication. They feel the anonymous fear and always keep themselves aloof fearing to transmit the virus to others. They do such things, and live their lives the way they even don't need. Most of them were found super conscious and cautious when using their utensils, bed, bathroom, clothes, and soap etc. However they know the ways of transmission, still they take very good care which is worth praising.

\section{Relevance of the Study}

AIDS is a socially constructed illness. From the beginning of the pandemic, HIV/AIDS has been socially constructed in stigmatizing ways resulting in negative perceptions of the virus and those who have it, as well as resulting in behaviors that reflects the stigmatization. HIV/AIDS-related stigma is "a term that refers to prejudice, discounting, discrediting, and discrimination directed at people perceived to have AIDS or HIV, and the individuals, groups, and communities with which they are associated" (Herek, 1999, 1106). This concealed nature of HIV infection is of basic importance when considering society's reaction to those infected. People infected by HIV conceal for two main reasons: to hide their positive status; and to keep secret the means by which they became infected. In his explanation of stigma, (Goffman 1963) calls this need to appear normal as 'passing'. So the HIV positive person may be stigmatized not solely for being positive, but also for suppositions regarding their sexual lifestyle, sexual orientation, and other stigmatizing characteristics such as drug use. It has been noted that the tactic of concealing a positive status is not an entirely adequate strategy for avoiding the pain of illness-related stigmas (Alonzo and Reynolds, 1995). This 'courtesy stigma' (Goffman, 1963) can result in further isolation of the family affected by HIV and AIDS, thus limiting their support networks when both emotional and physical help is needed. Partners will also have to consider whether they need to 'keep a secret' and to whom they may look for support without experiencing 'courtesy stigma'. Concealing HIV status can have a significant effect on whether or not an HIV-positive person seeks appropriate healthcare. Stigma and social exclusion can limit access to health and social services, and this is equally true of seronegative partners who often feel they are 'invisible' to the services to which their seropositive partners have access (Van der Straten et al., 1998). In order to maintain conceal ability, individuals affected by HIV and AIDS use a number of strategies. Lying about the diagnosis to others, particularly outside of the immediate caregiving relationship, is notable.

\section{Research Methodology \&Theoretical Aspects}

The study of research has an exploratory research design. The main purpose of the study is to tackle with the social dimensions including social exclusion, stigma, courtesy stigma, and discrimination faced by the people living with HIV/AIDS in Kashmir Division of Jammu and Kashmir State. There can be several or may be different theoretical perspectives underpinning the situation and arguing for the subject. Like Emile Durkheim, a renowned social thinker has given a valid and penetrating attention to the moral dimensions of human behaviour. He believed that society is controlled by the morality, and it is the society which teaches the man morality. So 


\section{HIV/AIDS and Psychosocial Ostracism: A view from Kashmir}

according to this theory stigmatization is normal when a man goes against the moral or ethical dimensions of the society. Such is the case with HIV/AIDS. In order to maintain conceal ability, individuals affected by HIV and AIDS use a number of strategies. Of all the topics covered in this research, stigma may be the area in which communicators have the greatest comparative advantage to make a difference. The challenge is to identify the many and varied ways that stigma impedes prevention, testing, care, support, and treatment of HIV/AIDS in a given country and to directly address these issues through all communication interventions, be they mass media, community-based, or IPC/C.

\section{Sample of the Study}

The important question that should be answered in all sample surveys is "How many participants should be chosen for a survey"? However, the answer cannot be given without considering the objectives and circumstances of investigations. So the concerned study itself proved decisive and there was no such great hustle deciding the sample size or the number of respondents. Kashmir Division has a very less number of HIV positive patients, which is around 230 only including those, expired. But the numbers of patients who come to visit the ART cell Srinagar on regular basis and avail the services are around 90 local Kashmiris excluding Non-Kashmiris. So the sample size was itself described and sought out. But due to some communication gaps the sample size has been minimized to 50 all living with HIV. Time curtailments also stabilized the size on 50 .

\section{Data Collection}

While collecting the data most of help has been sought from health department, medical institutions, District hospitals, JKSACS (Jammu \& Kashmir State AIDS Control Society), related organizations, and the Supreme Head Medical Institution of Kashmir, SKIMS (Sher-i-Kashmir Institute of Medical Sciences), were is the only ART center in Kashmir division for HIV/AIDS patients as well. Almost all the HIV patients hailing from the Kashmir valley are supposed to come to SKIMS Srinagar, the Summer Capital of Jammu \& Kashmir to avail free medicinal facility, treatment, CD4 Tests, other related tests, counselling, and moral, ethical and emotional support. So the identification of cases was normal. A study was carried out by employing the Interview Schedule and Observation as methodological tools. To carry out this study, a positivist approach was utilized. Positivist approaches rely heavily on experimental and manipulative methods. The positivist position is grounded in the theoretical belief that there is an objective reality that can be known to the researcher, if she or he uses the correct methods and applies those methods in a correct manner. (Cohen and Crabtree, 2006).

\section{Conclusion}

HIV/AIDS is a social disease as well as a medical condition. The progression of AIDS as a medical disease runs parallel to the drastic and irreparable stigma and discrimination. AIDS has a

culminating effect on the social life and society as a whole. HIV/AIDS related Stigma and Discrimination has been as killing as the disease itself and even more than that. In India at many 


\section{HIV/AIDS and Psychosocial Ostracism: A view from Kashmir}

places the HIV positive patients have been forcefully evicted from their homes, their work places. Some have been denied health care and facilities. Some were disowned by their families and community. HIV positive was considered not less than a devil, off track, mischievous, unfaithful, unclean, unsocial, uncultured, misguided, immoral, and unethical. Stigma and discrimination are an attribute of human instincts, so a man wishes to live a life untouched with disgrace and dishonor. The man's instinctive tendency has made him filter out the dangers that put their survival at risk. This instinctive behaviour leads to stigmatize and discriminate against those we think and perceive as causing danger to not our existence only but to our human stature and attitudinal stance.

\section{Bibliography/Webliography}

"India Human Development Report 2011 (Towards Social Inclusion)" (PDF). IAMR, Planning Commission, Government of India.p. 257.Retrieved 5 April 2016.

'Stigma and Social Exclusion in Healthcare', edited by Caroline Carlisle, Tom Mason, Caroline Watkins, Elizabeth Whitehead. (2005).

Beasley, M. (2008).A sourcebook of HIV/AIDS prevention programs. Washington, DC .World Bank.

Boesten, J. (2009). Gender and HIV/AIDS critical perspectives from the developing world. Farnham, England. Ashgate.

Campbell, C. (1999). Women, families, and HIV/AIDS: A sociological perspective on the epidemic in America. Cambridge.Cambridge University Press.

Campbell, C. (2005). Understanding and challenging HIV/AIDS stigma. University of KwaZuluNatal. Durban.

Centers for Disease Control and Prevention (2013) ' Diagnoses of HIV Infection and AIDS in the United States and Dependent Areas, 2011'

Fisher, A., \&Foreit, J. (2002).Designing HIV/AIDS intervention studies: An operations research handbook. New York, NY.Population Council.

Gifford, A. (2005). Living well with HIV and AIDS (3rd ed.). Boulder, CO. Bull Pub.

Mason, Tom. Stigma and Social Exclusion in Healthcare. London: Routledge, 2001.

Miller, D. (2000). Dying to care? Work, stress, and burnout in HIV/AIDS care. London: Routledge.

N, J. (1997). The Impact of AIDS: Psychological and social aspects of HIV infection. Amsterdam: Harwood Academic.

N, J. (1999). Mental health and HIV infection psychological and psychiatric aspects. Print. London. UCL Press.

Stutterheim SE et al (2009, 13th November), 'HIV-related stigma and psychological distress: the harmful effects of specific stigma manifestations in various social settings', AIDS 23:17

U.S. National Library of Medicine, 2012

UNAIDS (2012) ' Global Report: UNAIDS Report on the Global AIDS Epidemic 2012'

UNAIDS (2012) ' Global Report: UNAIDS Report on the Global AIDS Epidemic 2012

UNAIDS (2013) ' Global Report 2013' 
UNAIDS Gap Report 2014; UNAIDS Fact Sheet 2014.

WHO/UNAIDS/UNICEF (2011) ,'Global HIV/AIDS Response: Epidemic update and health sector progress towards Universal Access 2011'

How to cite this article: M Iqbal (2016), HIV/AIDS and Psychosocial Ostracism: A view from Kashmir, International Journal of Indian Psychology, Volume 3, Issue 3, No. 5, DIP: 18.01.095/20160303 